\title{
Built Environment and Health
}

\author{
David Berrigan, PhD MPH [Office of the Associate Director] and Robin A. McKinno, MPA [Risk \\ Factor Monitoring and Methods Branch] \\ Applied Research Program, Division of Cancer Control and Population Sciences, National Cancer \\ Institute, Executive Plaza North MSC 7344, Bethesda MD 20892-7344
}

\begin{abstract}
In the last decade, there has been a growing research interest in the influence of the built environment on physical activity and diet. This research is generally based on an ecological model of health behaviors, and conceptualizes the built environment at a variety of levels- from properties of individual rooms to features of urban or regional transportation networks. The focus on the built environment and health behaviors related to energy balance has arisen from two aspects of public health and urban/suburban development: concern over trends in the prevalence of obesity and efforts from the planning and public health communities to link neighborhood characteristics to physical activity and diet.
\end{abstract}

Preventive Medicine has been a leading forum for studies of associations between the built environment and health and this issue, the third in a series, continues and extends this tradition with a diverse and absorbing collection of 15 articles. These articles represent studies conducted in eight countries; five in the United States, four in Australia, and the remainder in Canada, New Zealand, and four European locales. Most relate to physical activity, (mainly walking), although two address other transportation modes (bicycling and bus use), and two concern methods. Two of the 15 studies involve experimental approaches, 12 studies present crosssectional analyses, and there is one review article. Finally, almost all of the studies concern urban or mixed samples; rural environments are generally not addressed. These summary characteristics reflect, to some extent, the current stage of the science of the built environment, physical activity, and diet (Wendel-Vos et al., 2007; Story et al., 2008).

Most of the articles in this issue address active transportation, a topic with implications for policy concerning public health, climate change, and energy resources. In general the authors emphasize positive results such as the association of bicycling with bike lane connectivity (Titze et al., 2008) and increased overall walking among users of public transport (Villanueva et al., 2008). Some studies also indicate potential targets for changes to design characteristics or features of the transportation environment. For example, self-report of increased parking costs was associated with active commuting (Rodriguez et al., 2008) and stair case width appears to be associated with increased stair use (Eves et al., 2008). Therefore, changes in parking costs or stairway design could increase levels of active transport. However, most studies find that one or more candidate measures of the built environment are not associated with outcomes of interest and one study reports little or no evidence of associations between access to parks and physical activity among several measures of access (Witten et al., 2008). Null associations are common in studies of the built environment and physical activity (Wendel-Vos et al., 2007), but it is not yet clear why.

\footnotetext{
Publisher's Disclaimer: This is a PDF file of an unedited manuscript that has been accepted for publication. As a service to our customers we are providing this early version of the manuscript. The manuscript will undergo copyediting, typesetting, and review of the resulting proof before it is published in its final citable form. Please note that during the production process errors may be discovered which could affect the content, and all legal disclaimers that apply to the journal pertain.
} 
In addition to the ongoing societal challenges of obesity and climate change, results concerning active transportation at the population level may be of growing interest to policy makers because of the recent and swift rise in gas prices. Changes in transportation mode choice and therefore increases in active transportation seem highly likely to involve policy and economic factors as well as the built environment. However, a lack of explicit attention to economic and policy variables is notable in many recently published analyses of the built environment and physical activity from the public health research community. Economic incentives or disincentives such as the high cost and scarcity of parking in Amsterdam and New York or the implementation of fees for use of motorized vehicles on busy streets or in busy neighborhoods ('congestion pricing'), as in Singapore or more recently London, have the potential to immediately and dramatically influence prevalence of active transportation, including walking and bicycling. Naturally, such incentives and disincentives create intense policy debates and equally intense calls for more rigorous data because the effects of congestion pricing on mode choice and traffic volume can be very sensitive to subtle differences in implementation (Santos and Fraser, 2006).

This issue also examines physical activity-related methodological questions and topics related to the food environment. Several articles point to significant gaps in the literature such as reliance on participant perceptions of physical activity and safety environments, and scarce data concerning diverse populations, less developed countries, and the food environments of seniors. Ideas for future research are scattered throughout the issue and these ideas are likely to foreshadow much new work.

In addition to its focus on environment, physical activity, diet and health, the issue contains a thought provoking article addressing micro-environmental variables and health. Dijkstra et al. investigated the stress-reducing effects of plants in a health care setting (Dijkstra et al.,

2008). Their simple and elegant study clearly indicates that the beneficial effects of plants are mediated by the perceived attractiveness of the environment. Related studies have been pursued by psychologists, (Heerwagen and Orians, 1986; Joye, 2007); attention to the 'microenviroment' could contribute to healthy behavior and positive response to medical treatment.

Public health researchers have much to contribute to the integrated analysis of the health and environmental effects of modifying the built and policy environments. Few economic studies incorporate the potential benefits of changes in behaviors related to chronic disease, and epidemiologists have a rich tradition of rigor in developing measurement and analytical tools for behavior and the environment. This volume highlights the need for continued growth in interdisciplinary collaboration among the health, economic, planning and policy sectors and for the development of an experimental tradition in this literature.

\section{Reference List}

1. Wendel-Vos W, Droomers M, Kremers S, Brug J, van Lenthe F. Potential environmental determinants of physical activity in adults: a systematic review. Obes Rev 2007;8(5):425-440. [PubMed: 17716300]

2. Story M, Kaphingst KM, Robinson-O'Brien R, Glanz K. Creating healthy food and eating environments: policy and environmental approaches. Annu. Rev. Public Health 2008;29:253-272. [PubMed: 18031223]

3. Titze S, Stronegger WJ, Janschitz S, Oja P. Association of built-environment, social-environment and personal factors with bicycling as a mode of transportation among Austrian city dwellers. Prev. Med. 2008

4. Villanueva K, Giles-Corti B, McCormack G. Achieving 10,000 steps: A comparison of public transport users and drivers in a University setting. Prev. Med. 2008

5. Rodriguez DA, Aytur S, Forsyth A, Oakes JM, Clifton KJ. Relation of modifiable neighborhood attributes to walking. Prev. Med. 2008 
6. Eves FF, Lewis AL, Griffin C. Modelling effects of stair width on rates of stair climbing in a train station. Prev. Med. 2008

7. Witten K, Hiscock R, Pearce J, Blakely T. Neighbourhood access to open spaces and the physical activity of residents: A national study. Prev. Med. 2008

8. Santos G, Fraser G. Road pricing: lessons from London. Econ. Policy 2006;21(46):263-310.

9. Dijkstra K, Pieterse ME, Pruyn A. Stress-reducing effects of indoor plants in the built healthcare environment: The mediating role of perceived attractiveness. Prev. Med. 2008

10. Heerwagen JH, Orians GH. Adaptations to windowlessness - a study of the use of visual decor in windowed and windowless offices. Environ. Behav 1986;18(5):623-639.

11. Joye Y. Architectural lessons from environmental psychology: the case of biophilic architecture. Rev. Gen. Psychol 2007;11(4):305-328. 